\title{
FutureJournal
}

\section{A Formação de Redes de Empresas: O Caso da Região Central do Rio Grande do Sul - RS}

\author{
Guerino Antonio Tonin \\ Professor da Universidade Federal de Santa Maria, UFSM, Brasil. \\ guerinoatonin@gmail.com
}

Felipe da Silva Ravanello

Graduado em Administração pela Universidade Federal de Santa Maria, UFSM, Brasil. feliperavas@gmail.com

\section{Nilson César Bertóli}

Doutorando em Administração pela Universidade Federal de Santa Maria, UFSM, Brasil. nilcamb@hotmail.com

\author{
Stefania Tonin \\ Professora da Faculdade Integrada de Santa Maria, FISMA, Brasil. \\ stefaniatonin@gmail.com
}

\section{RESUMO}

No presente trabalho, aborda-se o processo de formação de redes entre pequenas e médias empresas (PMEs). A partir de evidências teóricas, a questão da pesquisa confrontada foi compreender como ocorre a formação de redes interorganizacionais horizontais. A pesquisa estudou e qualificou os fatores subjacentes à formação de redes horizontais de cooperação. No estágio de formação da rede, são analisados os fatores de motivação, escolha do grupo, papel da liderança e a confiança. Para verificar a experiência da formação das redes, o delineamento da pesquisa é de um estudo exploratório, com abordagem quantitativa e qualitativa. A pesquisa empírica foi conduzida por meio de entrevistas com os primeiros e atuais presidentes de nove redes horizontais na região central do estado do Rio Grande do Sul (RS). Também, para melhor entender o fenômeno e aprofundar o estudo aplicou-se um questionário junto aos empresários fundadores das redes. Nos resultados da pesquisa, evidenciou-se que pressões contingenciais, como a concorrência, a dificuldade de obter recursos tangíveis e intangíveis, a falta de crédito, o baixo volume de negócio, exercem influência na 


\section{FutureJournal}

motivação para formar redes, que buscam complementaridade de conhecimentos e resultados econômicos.

PALAVRAS-CHAVE: Cooperação. Formação. Redes horizontais.

\section{Formation of Business Networks: The Case of the Central Region of Rio Grande Do Sul State - RS}

\section{ABSTRACT}

This paper addresses the issue of the process of formation of networks between Small and Medium Enterprises. From theoretical evidence, confronted the research question was to understand how horizontal inter-organizational networks are formed. The survey studied and described the factors underlying the formation of these networks. In the formation stage, motivating factors are analyzed to choose the group, leadership roles and trust level. To verify the network formation experience, the design of the research is an exploratory study, with qualitative and quantitative analysis. Empirical research was conducted through interviews with former and current presidents of nine horizontal networks in the Central Rio Grande do Sul State (RS). Also, to better understand the phenomenon and further study a questionnaire was applied with the entrepreneur founders of the network. The survey results show that the contingency pressures, such as competition, the difficulty of obtaining tangible and intangible resources, lack of credit, the low volume of business, influenced the motivation to form networks, in seeking complementary knowledge and financial results.

KEY-WORDS: Cooperation. Formation. Horizontal networks. 


\section{INTRODUÇÃO}

A necessidade de sobrevivência no mundo corporativo tem forçado as empresas a adotarem novos formatos organizacionais. Assim, fusões, alianças estratégicas, aquisições, parcerias, redes e aglomerações estão presentes nos trabalhos de pesquisadores no mundo inteiro, resultando em produções teóricas importantes no âmbito da análise interorganizacional (Cunha, 2002).

Nos arranjos coletivos, o desafio dos administradores é fazer as empresas atingirem, juntas, objetivos que não conseguiriam alcançar sozinhas. Verifica-se o deslocamento do modelo centrado na firma para modelos centrados em redes que transformam o modo de as empresas se relacionarem, permitindo a cooperação entre elas em diversas atividades (Grewal, 2008). Nesse cenário, o sucesso empresarial é uma conquista essencialmente coletiva. Para Kleindorfer e Wind (2012), as redes mudam os conceitos fundamentais pelos quais são entendidos os negócios e o mundo que nos cerca. Caracterizam o desenho estrutural de organização em rede, em particular em rede interorganizacional horizontal, empresas com objetivos comuns, formalmente constituídas, com prazo ilimitado de existência, onde cada participante mantém sua individualidade legal, as decisões têm a participação de todos e resultados e ganhos da cooperação são simetricamente divididos (Verschoore \& Balestrin, 2008). Dessa forma, empresas de diferentes tamanhos e segmentos percebem nas redes de cooperação um caminho estratégico de aumentar sua competitividade no mercado e superar suas limitações, obter escala, adquirir recursos e ter acesso a novas tecnologias.

A fim de atender a tais demandas e levar o fortalecimento da cooperação, surge a necessidade de compreender os fatores de formação das redes. Além disso, de acordo com Verschoore (2004), a carência de pesquisas sobre a formação dos arranjos organizacionais em redes parece representar uma oportunidade para a realização de trabalhos nessa perspectiva. Assim, esse cenário levou à seguinte questão de pesquisa: Como ocorre a formação de redes interorganizacionais horizontais? Com 
relação ao objetivo principal, o presente trabalho visa analisar a formação, de redes de empresas. Como objetivos específicos, busca-se: identificar as características das redes estudadas; verificar a motivação que levou à formação das redes; verificar que fatores são determinantes na formação das redes. Nesse sentido, esta pesquisa oferece alguns insights sobre a formação de redes e contribui aos estudos teóricos organizacionais sobre formação de redes de cooperação interorganizacionais.

\section{FUNDAMENTAÇÃO TEÓRICA}

Diante das transformações sociais, econômicas e de mercado, onde se sobressai o acirramento da concorrência, as empresas dos mais diversos setores da economia estão buscando, na cooperação, a garantia de sua expansão ou, ao menos, de sua sobrevivência. Trata-se de uma necessidade que o ambiente lhes impôs de se tornarem competitivas, uma maneira econômica e racional de fazer negócio. Amato Neto (1999) destaca que aglomerados de empresas trazem ganhos de eficiência coletiva, dificilmente alcançável por produtores isolados, pois em contextos de arranjos produtivos locais, segundo Lastres e Cassiolato (2005), ocorre o intercâmbio sistemático de informações produtivas, tecnológicas e mercadológicas pela interação de desenvolvimento de programas comuns e de projetos conjuntos.

Nesse contexto, principalmente, as micro e pequenas empresas podem, unidas por redes horizontais, alcançar economia de nível superior às suas capacidades individuais e ganhar mais poder para compra de insumos, realização de marketing conjunto e também atendimento de pedidos de grande escala (Santos, Crocco \& Lemos, 2002).

Independentemente de outras formas denominadas "organização em redes", o conceito aqui usado refere-se à rede interorganizacional horizontal como um conjunto de empresas independentes entre si, constituindo uma forma associativa única, a qual forma uma organização tão importante ou mais do que a própria empresa participante. Seu propósito principal é o de reunir em uma única estrutura as características essenciais para ser competitiva (Verschoore, 2004) e que, no dizer de 
Wegner e Padula (2010), geralmente, envolve empresas do mesmo setor que permanecem juridicamente independentes e cooperam em aspectos predefinidos. Essa forma de organização em redes representa um tipo próprio de união, de natureza horizontal, de atores diferentes, que se unem para implantar estratégias de interesse coletivo. As redes horizontais caracterizam-se pela colaboração entre empresas que atuam na mesma fase da cadeia produtiva, atravessam organizações similares, realizando em conjunto atividades comuns ao grupo para alcançar fins coletivos (Wegner, Maciel, Schmitt \& Wittmann, 2004). Aproxima-se do conceito de rede de Provan, Fish e Sydow (2007), definido como um tipo específico de rede pouco pesquisado, que consiste da união de um grupo, normalmente pequeno, de empresas conectadas para a realização de objetivos comuns. Como ressaltam Pereira, Venturini e Visentini (2006), a formação de redes horizontais visa a fins coletivos que serão alcançados por relações de interdependência.

Porém, dada a independência dos parceiros, as razões para formar a alianças podem não convergir. Conquanto as empresas possuam objetivos diferentes para ingressar numa rede, os critérios e as medidas de desempenho em rede podem ser divergentes. Keil (2000), em sua análise sobre objetivos das empresas que formam parcerias, combinou-os em três formas que podem ser: os mesmos ou muito similares, compatíveis e conflituosos. Objetivos similares são mais prováveis de serem alcançados simultaneamente por estarem justamente relacionados. Na formação de redes entre empresas, é necessário considerar que cada empresa forma uma identidade única (Verschoore, 2004), com seus valores e estilo próprio de gestão que devem ser respeitados pelo grupo.

No entendimento de Crook (2012), a organização em rede "não pode ser formada a partir de um grupo de componentes ou agentes díspares ou desvinculados". Estabelecer relações interorganizacionais cooperativas tem sido uma importante orientação estratégica para as empresas de todos os tamanhos e segmentos. Clareza sobre a motivação, a visão e os objetivos do novo empreendimento permite esclarecer quem deveria participar da rede e quem não deveria, quando as empresas tomam a decisão de constituir-se em rede de cooperação (Ritter \& Gemünden, 
1998; Leana \& Pil, 2006; Shipilov, Rowley \& Aharonson, 2006). Observouse que as principais motivações que levaram as empresas a participar de redes foram necessidade de sobrevivência, acesso a novos recursos e a busca de competitividade (Provan et al., 2007; Parmigiani \& Rivera-Santos, 2012). Trata-se de uma necessidade que o ambiente impõe de se tornarem competitivas, de uma estratégia de sobrevivência e desenvolvimento das empresas (Almeida Filho, 2005).

Como afirma Amato Neto (1999), a formação de redes de cooperação, além dos benefícios, aporta desafios, e um dos principais é conseguir, na prática, a confiança mútua entre as empresas. Assim, uma das primeiras funções na gestão interorganizacional é identificar e atrair novos parceiros com potencial de acrescentar efetiva contribuição à rede, com recursos que possam agregar valor no relacionamento, e haver disposição de compartilhá-los (Shipilov et al., 2006). Segundo Hill (2003), é necessário definir claramente quais os critérios de quem deveria participar e quem não deveria, quando as empresas tomam decisões sobre alianças estratégicas, terceirização e aquisições. No entendimento de Shipilov et al. (2006), é importante que os potenciais parceiros tenham um perfil adequado para adaptar-se à cultura cooperativa, aos objetivos e à estratégia da rede.

Nesse contexto, construir essas relações em um ambiente de valores diferentes e empresas interligadas em rede exige dos líderes compreender essas diferenças de valores e saber administrá-las (Palmer, 2012). O estilo de liderança exercido com sucesso nas organizações hierárquicas não obtém o mesmo êxito nas redes, então, o desafio é saber que tipo de habilidades de liderança exigem as redes, em especial, nos diferentes estágios de sua formação, evolução, crescimento e consolidação (Palmer, 2012). Dado que a rede tem como característica a ausência de uma hierarquia formal, a liderança da rede deve ter a cultura do compartilhamento, da divisão do poder e da informação no processo decisório, ser flexível, proativa, motivadora e incentivadora, a fim de manter a coesão interna da rede horizontal, tendo como foco os valores e os interesses comuns (Lipman-Blumen, 1999). 
Outro aspecto fundamental na formação de redes interorganizacionais destacado na revisão da literatura é a confiança. Para Gulati (1995), trata-se de um fenômeno interpessoal, inerente às relações sociais, presente nas redes interorganizacionais, entendidas como agrupamentos sociais. Confiança interpessoal contribui para a construção de conhecimentos em contextos onde há grande incerteza e ambiguidade (Balestro, 2004). Balestrin (2005) indica algumas características no contexto das redes de pequenas empresas que estabelecem um ambiente vantajoso para a geração e aumento de confiança entre as firmas e que permitem alcançar vantagem econômica pelo crescimento das vendas e pelos ganhos marginais, são elas: a existência de compartilhamento de informações sobre mercados, tecnologias e lucratividade; a pouca diferença de tamanho, poder ou posição estratégica entre as firmas; a adoção de processos e técnicas similares; a alternância periódica da liderança para representar o conjunto das empresas; a construção de relações de longo prazo; a ocorrência de recompensa financeira semelhante para as firmas e empregados dentro delas; e a experiência coletiva.

Os fatores conceituais de motivação para formação de redes, escolha dos parceiros, papel da liderança e construção de confiança aprofundados neste capítulo terão caráter de orientar a pesquisa com a finalidade de compreensão de como ocorre a formação de redes.

\section{METODOLOGIA}

O trabalho apresentado é de natureza exploratória e procura compreender o comportamento do objeto estudado para a confirmação ou não de ideias prévias, pois busca familiarizar-se com o tema, com a finalidade de identificar e compreender a percepção dos participantes (fundadores das redes, primeiros presidentes e presidentes atuais) das redes pesquisadas por meio de questionário e de entrevista com aqueles que vivenciaram, na prática, o processo de formação das redes.

Como estratégia de observação do objeto de estudo, neste trabalho serão usados tanto dados quantitativos (questionários) quanto qualitativos (entrevistas). Quanto à unidade de análise, são as redes situadas na região 
central do estado do Rio Grande do Sul. A seleção da amostra foi intencional e constituída de nove redes mais antigas fundadas na região. A escolha dessas unidades de análise deve-se ao entendimento de que, por serem as pioneiras, possam apresentar um melhor entendimento do fenômeno da formação das redes e importantes elementos de análise do objeto de estudo.

Os dados primários quantitativos foram coletados junto às empresas fundadoras das redes e os qualitativos, por meio de entrevistas semiestruturadas com os primeiros e atuais presidentes das redes e de observações do pesquisador em reuniões das redes; as conclusões limitarse-ão unicamente ao contexto das redes. Foi realizado pré-teste dos instrumentos de coleta de dados em três redes com características similares às das redes estudadas.

Foram realizadas 13 entrevistas com presidentes de redes, seis com os primeiros presidentes e sete com os presidentes atuais. Os questionários foram aplicados a 67 empresários formadores de redes e que ainda estão nelas, conforme dados do Quadro 1. As entrevistas foram gravadas, transcritas e, posteriormente, analisadas.

\begin{tabular}{|c|c|c|c|c|c|}
\hline REDES & $\begin{array}{c}\text { Primeiros } \\
\text { presidentes }\end{array}$ & $\begin{array}{c}\text { Presidentes } \\
\text { atuais }\end{array}$ & Fundadores & Permanecentes & Respondentes \\
\hline A & A1 & A2 & 12 & 10 & 06 \\
\hline B & B1 & B1 & 20 & 07 & 05 \\
\hline C & C1 & C2 & 12 & 12 & 12 \\
\hline D & D1 & D2 & 06 & 06 & 06 \\
\hline E & E1 & & 12 & 12 & 11 \\
\hline F & F1 & & 32 & 06 & 04 \\
\hline G & & G2 & 19 & 11 & 09 \\
\hline H & & H2 & 09 & 07 & 06 \\
\hline I & & I2 & 10 & 08 & 08 \\
\hline Total & $\mathbf{6}$ & $\mathbf{7}$ & $\mathbf{1 3 2}$ & $\mathbf{7 9}$ & $\mathbf{6 7}$ \\
\hline
\end{tabular}

\section{Quadro 1: Distribuição das entrevistas e dos questionários aplicados nas redes estudadas}

Fonte: Elaborado pelos autores

\section{ANÁlISE DOS RESULTADOS DA PESQUISA}

Os resultados da pesquisa foram analisados em conformidade com os seguintes tratamentos: estatística descritiva dos dados e análise de conteúdo. Para a análise quantitativa, faz-se relevante identificar o Alfa de Cronbach, atestando a confiabilidade do instrumento da pesquisa. Hair, 
Babin, Money e Samouel (2005) relatam que tal medida varia de 0 a 1 , sendo os valores acima de 0,60 aceitáveis. Todas as variáveis estudadas, excetuando-se a variável liderança, estão acima de 0,60 , o que não permite afirmações conclusivas sobre tal variável.

\subsection{CARACTERIZAÇÃO DAS REDES PESQUISADAS}

As redes estudadas têm significativo tempo de mercado, com idade que varia de oito a 18 anos de existência e foram constituídas por número reduzido de participantes, conforme pode ser visto no Quadro 2.

\begin{tabular}{|c|c|c|c|c|}
\hline Redes & $\begin{array}{c}\text { Ano de } \\
\text { fundação }\end{array}$ & Anos & Fundadoras & Permanecentes \\
\hline A & 1996 & 18 & 12 & 10 \\
\hline B & 2000 & 14 & 20 & 07 \\
\hline C & 2004 & 10 & 12 & 12 \\
\hline D & 2005 & 09 & 06 & 06 \\
\hline E & 2005 & 09 & 12 & 12 \\
\hline G & 2005 & 09 & 32 & 06 \\
\hline H & 2006 & 08 & 19 & 07 \\
\hline I & 2006 & 08 & 09 & 08 \\
\hline
\end{tabular}

Quadro 2: Relação da idade das redes, número de empresas fundadoras e número de empresas fundadoras que permanecem na rede

Fonte: Elaborado pelos autores

Uma das razões que podem explicar o elevado número de redes jovens pesquisadas é o fato de que, em 2004, o governo do estado do Rio Grande do Sul levou à região central do estado o Programa Redes de Cooperação, por meio da Secretaria de Desenvolvimento e Assuntos Internacionais (Sedai). Assim, o governo do estado, por meio da Sedai, foi o ator de maior relevância na formação de redes na região, num total de 26 , dentre as quais sete são objeto deste estudo.

Verifica-se que poucos dos fundadores saíram da maioria das redes, três delas continuam com todos os empresários fundadores e outras três tiveram baixas reduzidas, evidenciando o acerto na escolha dos participantes que constituíram as redes e sua adaptação à cultura da cooperação. As redes constituídas por um grupo maior de participantes, foram as que perderam mais parceiros fundadores, por diversas razões, 
entre elas, falhas na seleção e tamanho maior, que dificulta conhecer melhor os futuros parceiros e suas reais condições de adaptação aos objetivos da parceria.

\subsection{TAMANHO E SEGMENTO DE NEGÓCIO DAS REDES}

As redes pesquisadas estão em diferentes segmentos de atividades, sendo sete no setor de serviços e duas no setor industrial. Verifica-se que algumas redes tiveram significativo crescimento e outras permaneceram praticamente estáveis ou até decresceram em número e participantes.

\begin{tabular}{|c|c|l|}
\hline Redes & Número de empresas & \multicolumn{1}{|c|}{ Segmento de negócio } \\
\hline A & 30 & Supermercados \\
\hline B & 13 & Comércio de Material de Construção \\
\hline C & 34 & Comércio de Artigos Esportivos \\
\hline D & 06 & Indústria de Serralheria e de Aberturas de Alumínio \\
\hline E & 16 & Indústria de Produção e Beneficiamento de Arroz \\
\hline F & 06 & Corretoras de Seguros \\
\hline G & 20 & Comércio de Pneus \\
\hline H & 07 & Comércio de Combustíveis \\
\hline I & 11 & Imobiliário \\
\hline Total & $\mathbf{1 4 3}$ & \\
\hline
\end{tabular}

\section{Quadro 3: Número de empresas por rede estudada e segmento de} atuação

Fonte: Elaborado pelo próprio autor

\subsection{FATORES INFLUENCIADORES NA FORMAÇÃO DE REDES INTERORGANIZACIONAIS HORIZONTAIS}

Entre os aspectos importantes a serem destacados na articulação dos empresários no processo de formação de redes e de acordo com o referencial teórico, estão: motivação, escolha dos parceiros, papel da liderança e construção da confiança.

\subsubsection{Motivação na formação de redes interorganizacionais horizontais}

Em uma escala de 01, para discordância total, e 05, para concordância total, os empresários criadores das redes pesquisadas mostraram que a motivação na formação das redes foi a esperança de 
sobrevivência e crescimento, pois as empresas encontravam dificuldades de competitividade em um mercado de incertezas e em transformação imposta pela concorrência, como mostram os dados da pesquisa com média de 4,12 dos respondentes, conforme a Tabela 1.

\section{Tabela 1: Fatores motivacionais dos empresários em participar de redes}

\begin{tabular}{ll|c|c|c|c|c|c|c}
\hline Fatores & $\mathbf{N R}$ & $\begin{array}{c}\mathbf{D T}^{\mathbf{1}} \\
\mathbf{( 1 )}\end{array}$ & $\begin{array}{c}\mathbf{D}^{\mathbf{2}} \\
\mathbf{( 2 )}\end{array}$ & $\begin{array}{c}\mathbf{I}^{\mathbf{3}} \\
\mathbf{( 3 )}\end{array}$ & $\begin{array}{c}\mathbf{C}^{\mathbf{4}} \\
\mathbf{( 4 )}\end{array}$ & $\begin{array}{c}\mathbf{C T}^{\mathbf{5}} \\
\mathbf{( 5 )}\end{array}$ & Média \\
\hline $\begin{array}{l}\text { Reduzir incertezas e fortalecer as } \\
\text { empresas frente à concorrência }\end{array}$ & 2 & 1 & 4 & 10 & 21 & 29 & $4,12(3)$ \\
\hline Resultado econômico & 1 & 3 & 4 & 17 & 23 & 19 & $3,77(6)$ \\
\hline Acesso a inovação e tecnologias & 1 & 1 & 2 & 2 & 19 & 42 & $4,50(1)$ \\
\hline Estratégia de sobrevivência no mercado & 2 & 2 & 4 & 19 & 19 & 21 & $3,80(5)$ \\
\hline $\begin{array}{l}\text { Redução de custos e obtenção de } \\
\text { benefícios }\end{array}$ & 3 & 2 & 3 & 10 & 14 & 35 & $4,20(2)$ \\
\hline $\begin{array}{l}\text { Ter acesso a eficiência, aprendizagem e } \\
\text { competências complementares }\end{array}$ & 1 & 1 & 1 & 15 & 25 & 24 & $4,06(4)$ \\
\hline $\begin{array}{l}\text { Valorização da empresa no mercado } \\
\text { Baixo crescimento }\end{array}$ & 1 & 3 & 3 & 15 & 28 & 17 & $3,80(5)$ \\
\hline $\begin{array}{l}\text { O grupo inicial reduzido favoreceu o } \\
\text { entendimento sobre as vantagens da } \\
\text { união }\end{array}$ & 3 & 0 & 2 & 8 & 34 & 20 & $4,12(7)$ \\
\hline
\end{tabular}

1- NR - Não Respondeu; DT - Discordo Totalmente; 2 - D - Discordo; 3 - I Indiferente; 4 - C - Concordo; 5 - CT - Concordo Totalmente.

Fonte: Elaborado pelos autores

O sentimento era de que juntas seria muito mais fácil superar os problemas, por meio de acesso a inovações tecnológicas (média 4,50), aprendizagem e competências complementares (média 4,06). Obter uma maior eficiência por meio da redução de custos e, consequentemente, valorização da empresa no mercado (média 3,80) e obtenção de benefícios (média 4,20) são outros motivos valorizados pelos empresários em participar das redes. Dessa forma, pela união, as empresas trocam recursos, experiências e conhecimentos com os parceiros, que se traduzem em melhorias na eficiência empresarial e no resultado econômico, com média de 3,77 .

Esses dados são corroborados pelos entrevistados que caracterizam a instabilidade ambiental como uma das razões para criar a união de empresas e descrevem o ambiente econômico como instável e desfavorável aos negócios. 
A economia brasileira vivia um período de baixo crescimento, que influenciava o baixo desempenho das empresas "e isso se refletia também no setor da construção civil" (D1) e também afetava o setor arrozeiro, que operava com baixas margens de lucratividade. "Na época o setor do arroz vivia em crise e as pequenas empresas estavam sendo 'engolidas' pelo sistema" (E1). "A rede foi a forma que encontramos para aumentar o nosso poder de barganha, contribuir para superar as dificuldades vividas pelo setor" (E1).

Segundo o primeiro Presidente da empresa A, a principal razão para formar a rede foi fortalecer as empresas, diante da chegada da concorrência de grupos estrangeiros. "Não tínhamos alternativa senão a união para enfrentarmos a concorrência, caso não quiséssemos desaparecer". O fato é reforçado pelo atual Presidente da rede: "O objetivo principal da rede era associar pequenas empresas, para que juntas pudessem adquirir força para concorrer e fazer frente a grandes grupos internacionais que estavam se estabelecendo em nossa cidade e nos tornarmos mais competitivos". O aumento da concorrência, a presença de novos entrantes no mercado de material de construção civil, conscientizou empresários do setor sobre a importância de trabalharem unidos. "Então, a união surgiu como forma de enfrentar a concorrência, para obter melhores preços, alavancar melhor a logística das empresas, comprar em conjunto." (B1).

Para os dirigentes das empresas A, B e F, a motivação de participar das redes foi a estratégia de sobrevivência, ideia corroborada pelos empresários formadores das redes com média de 3,80, pois as empresas tinham problemas de competitividade em um mercado ameaçado pela concorrência de grandes grupos. Para alguns dirigentes, é graças às redes que algumas empresas ainda existem. "Eu acredito, se as empresas não estivessem em rede, muitas estariam fechadas." (B2). A necessidade maior recai sobre a possibilidade de acessar recursos intangíveis, tais como: conhecimento de mercado (clientes, representantes, fornecedores, tecnologia), conhecimento de gestão e técnicas de produção e vendas. Essas percepções são evidenciadas pelos dados quantitativos da pesquisa, que mostram que os recursos intangíveis estão entre os principais motivos de os empresários participarem da rede com média de 4,50 e média de 
4,06 para inovação, competências complementares, novas tecnologias e aprendizagem. Assim, os dados mostram que outras razões, não monetárias, estão presentes na formação de arranjos cooperativos.

Verifica-se que as redes são criadas com o propósito de cooperar para obter vantagens competitivas, viabilizadas pela troca de informações entre as empresas, pelo estabelecimento de um intercâmbio de ideias, pelo desenvolvimento de uma visão estratégica, pelo compartilhamento de recursos e pelo desenvolvimento de competências-chave.

Os achados mostram também que os empresários formam parcerias com o objetivo de reduzir custos e obter vantagens materiais e econômicas com média de 4,20, segundo aspecto mais valorizado pelos empresários formadores da união, conforme a Tabela 1. O ganho de eficiência empresarial, pela redução de custos, compras em conjunto, compartilhamento de recursos e acesso à mídia, foi indicado pelos seis primeiros presidentes entrevistados como um fator altamente valorizado pelas empresas formadoras das redes.

As entrevistas com os primeiros dirigentes das redes evidenciam que a possibilidade de obter conhecimento pela interação dos diversos atores e acesso a novos mercados estão entre os principais motivos para as empresas entrarem em rede. "A nossa rede foi formada para agregar conhecimentos, trocar experiências, fortalecer as empresas e o grupo, melhorar suas práticas gerenciais e realizar ações em conjunto, como, por exemplo, compras, este, inicialmente, o objetivo principal da rede." (D1). Uma das unanimidades entre os entrevistados foi o conhecimentos a que tiveram acesso a partir da entrada na rede. Os dados mostram que algumas características têm contribuído para a crescente motivação dos empresários em participar de estratégias cooperativas, como necessidade de as empresas se manterem fortes em seus mercados e se adaptarem às necessidades regionais, rápido desenvolvimento tecnológico que leva a ciclos de vida de produtos mais curtos, maior demanda por soluções que envolvem diversos tipos de competências, ofertas de produtos e serviços de melhor qualidade, e emergência de novos concorrentes.

Outra razão apontada está na orientação interna ao buscar uma melhor performance na eficiência organizacional, com média de 4,06, 
conforme dados da Tabela 1. A eficiência organizacional é uma questão fundamental para a formação de redes interorganizacionais como fator de redução de custos e melhoria dos processos operacionais. Outros fatores motivadores para a formação de redes identificados referem-se a incertezas do mercado em relação a acesso a novas tecnologias, exigências dos consumidores em relação à qualidade de produtos/serviços oferecidos e ampliação do mercado de atuação. As ideias aqui desenvolvidas mostram que é profuso e diverso o espectro de objetivos perseguidos pelas empresas no processo de cooperação.

\subsubsection{Escolha do grupo formador de redes interorganizacionais horizontais}

Uma tarefa que exige cuidados especiais na formação dos arranjos interorganizacionais é a definição de quem deve fazer parte do coletivo. Falhas na escolha dos parceiros trazem, normalmente, dificuldades de funcionamento. Atrair parceiros já conhecidos e iniciar redes com número reduzido de parceiros foram estratégias usadas para iniciar redes de cooperação, conforme Tabela 2.

\section{Tabela 2: Fatores considerados pelos empresários na escolha do grupo formador de redes}

\begin{tabular}{lccccccc}
\hline Fatores & NR & DT & D & I & C & CT & Média \\
& & (1) & (2) & (3) & (4) & (5) & \\
& & & & & & & \\
& & & & & & & \\
\hline O grupo já se conhecia antes de formar a rede & 4 & 12 & 10 & 19 & 12 & 10 & $2,97(2)$ \\
Número limitado de participantes na formação & 2 & 0 & 2 & 8 & 34 & 20 & $4,12(1)$
\end{tabular}

Fonte: Elaborado pelos autores

Em geral, a formação de redes passa por uma fase de contatos iniciais e seleção de potenciais integrantes. Os entrevistados (primeiros presidentes) declararam que havia incertezas sobre quem convidar para fazer parte do grupo. Isso, devido, principalmente, a dois aspectos: a) ausência de clareza sobre a visão e os objetivos do novo empreendimento; 
e b) falta de definição clara dos critérios de quem deveria fazer parte da rede. O pouco conhecimento de como deveria funcionar o novo empreendimento gerava incertezas sobre a escolha dos agentes da respectiva união ( $B 1, C 1, E 1$ e $F 1)$. A única certeza era que fossem empresas reconhecidas como idôneas pelo mercado (A1, B1, C1, E1 e F1).

O cuidado reside na escolha de parceiros que agreguem valor e que possibilitem vislumbrar a probabilidade de atingir ações coordenadas entre as empresas. Buscar informações sobre os futuros parceiros junto a fornecedores e outros empresários foram estratégias utilizadas pela liderança formadora das redes para conhecer a credibilidade de quem poderia ser convidado para participar do grupo. Dessa forma, o objetivo foi atrair parceiros que tivessem condições de agregar valor ao relacionamento e disposição para compartilhá-lo (A1, B1, C1).

Tanto o primeiro Presidente da rede A como o da rede $\mathrm{B}$ declararam que tiveram cuidados em limitar o número inicial de participantes, a fim de facilitar a compreensão da filosofia da cooperação e agilizar a construção da rede. Essa percepção é confirmada pelos empresários formadores da rede, que, pelo fato de o grupo ser reduzido, facilitou as discussões e a criação da rede, com média de 4,12, como mostram os dados da Tabela 2.

No entanto, algumas redes tiveram problemas no processo de escolha dos parceiros. Destaca-se, neste caso, a pressão sofrida pelos consultores do Programa Redes de Cooperação com metas numéricas de formação de redes por ano, o que pressão dificultou especialmente a seleção de empresas com reais potencialidades e condições de participar do grupo.

As evidências mostram que as redes pesquisadas tiveram forte preocupação com seriedade, responsabilidade e idoneidade na escolha dos empresários que deveriam fazer parte do grupo formador da união. "Quanto aos critérios da escolha dos parceiros para fazer parte do grupo, sempre prevaleceram seriedade e honestidade. O parceiro precisa ser sério dentro do negócio dele." (A1). Além disso, os depoimentos demonstram a valorização de parceiros que agreguem valor e que possibilitem o alcance de ações coordenadas entre as empresas, assim o acerto na escolha dos 
parceiros é um dos fatores responsáveis pelo sucesso da formação da rede e de sua continuidade.

\subsubsection{A liderança na formação de redes interorganizacionais horizontais}

No período da criação da rede, há diversas incertezas: é o momento que, dada a ausência da autoridade formal, a presença da liderança assume papel relevante. O papel da liderança é conduzir o processo, esclarecer dúvidas, criar condições de debate aberto e, principalmente, envolver e motivar o grupo sobre a importância do novo empreendimento. Diversas qualidades de liderança foram identificadas entre as redes pesquisadas: reputação, preparação e conhecimento sobre parcerias, conforme Tabela 3.

\section{Tabela 3: Fatores considerados importantes sobre a liderança na formação de redes}

\begin{tabular}{l|c|c|c|c|c|c|c}
\hline Fatores & NR & $\begin{array}{c}\text { DT } \\
(\mathbf{1})\end{array}$ & $\begin{array}{c}\text { D } \\
(\mathbf{2})\end{array}$ & $\begin{array}{c}\text { I } \\
\mathbf{( 3 )}\end{array}$ & $\begin{array}{c}\text { C } \\
\mathbf{( 4 )}\end{array}$ & $\begin{array}{c}\text { CT } \\
\mathbf{( 5 )}\end{array}$ & Média \\
\hline Reputação do líder & 4 & 1 & 3 & 15 & 27 & 17 & $\begin{array}{c}3,89 \\
(1)\end{array}$ \\
\hline Preparação do líder para orientar o grupo & 5 & 4 & 5 & 19 & 25 & 9 & $\begin{array}{c}3,43 \\
(3)\end{array}$ \\
\hline Conhecimento sobre redes e seus benefícios & 5 & 3 & 7 & 16 & 25 & 11 & $\begin{array}{c}3,49 \\
(2)\end{array}$ \\
\hline $\begin{array}{l}\text { Conhecimento sobre as dificuldades de } \\
\text { cooperação }\end{array}$ & 5 & 4 & 5 & 19 & 25 & 9 & $\begin{array}{c}3,43 \\
(3)\end{array}$ \\
\hline
\end{tabular}

Fonte: Elaborado pelos autores

De acordo com dados da Tabela 3, a reputação aparece como a credencial mais importante da liderança, com média de 3,89, para orientar o grupo na sua fase inicial. As relações humanas, as boas relações em grupo representam desafio permanente que envolve diálogos entre os pares e avanços do conhecimento mútuo. Nesse sentido, a imagem positiva do líder e sua preparação, com valorização média de 3,43, são credenciais essenciais da liderança para orientar o grupo na construção da parceria. 0 desafio do líder é conseguir a identificação de propósitos em grupo, de valores e de querer estar junto para conseguir objetivos de grupo. O conhecimento do condutor do grupo sobre redes e seus benefícios (média 
de 3,49) e sobre as dificuldades de cooperação entre empresas concorrentes (média de 3,43) ajuda a esclarecer sobre as vantagens e o envolvimento necessários do grupo.

Os dados evidenciam que, no processo de formação da rede, a influência da liderança não é restrita a uma única pessoa. "Durante a formação da rede, evidentemente, existiam no grupo algumas pessoas mais entusiasmadas quanto à viabilidade da rede e se destacavam pela contribuição de suas ideias." (A1). Constata-se, assim, o aparecimento da liderança coletiva que envolve todos na obrigação de contribuir para que o futuro arranjo dê certo e ofereça os benefícios esperados.

Outros depoimentos mostram que a presença de um líder proeminente e articulador durante o processo de construção da rede é fundamental para formar redes de cooperação entre empresas. "Eu liderei o processo de construção da rede. Fiz contatos com lojistas e com fornecedores, pedindo a eles que nos indicassem potenciais lojistas do estado do Rio Grande do Sul que poderiam fazer parte do grupo." (C1). Outro entrevistado afirmou ter liderado o processo de formação da rede. "A iniciativa partiu de mim. [...] Foi um trabalho árduo convencer o pessoal a trabalhar um tema desconhecido da maioria. Os empresários estão acostumados a trabalhar individualmente. A ideia de operar em conjunto foi algo estranho e que assustou no início." (E1). O desafio da liderança foi de superar a desconfiança e fazer as empresas entenderem que juntas conseguiriam atingir objetivos que não conseguiriam alcançar individualmente. A colaboração dos consultores do Projeto Redes de Cooperação foi fundamental no processo, pelos esclarecimentos e pelo conhecimento que tinham sobre como seria trabalhar em grupo de forma cooperada. As evidências mostram que a liderança é considerada fundamental no processo de formação das redes estudadas, quer exercida de forma coletiva, quer individual.

Foram necessários significativos esforços da liderança para sustentar a formação das redes, segundo depoimento do entrevistado E1: "A problemática de rede não basta levantar uma bandeira de vantagens competitivas para criar um ambiente de cooperação. Torna-se necessário muito esforço e trabalho para convencer os empresários num projeto 
comum de futuro incerto". Essas evidências iniciais indicam que existe pouca atividade de cooperação entre as empresas durante o processo de formação de redes e que os elos, nesse estágio, são tênues.

O exercício da liderança articula e motiva o grupo, levando conhecimentos sobre o funcionamento da futura parceria. "A liderança assegura comprometimento de todos no processo de constituição da rede." (F1). Segundo os entrevistados, uma grande dificuldade encontrada pelos líderes na formação de redes foi trabalhar com pessoas de perfil diferente, ideias diferentes, sistemas diferentes e convencê-las a trabalhar da mesma forma. "A maior dificuldade, o maior problema, é você mudar a cabeça das pessoas que já vêm trabalhando dentro de um sistema, fazer que elas mudem e mostrar que a mudança vai trazer melhorias." (F1). Dessa forma, no momento em que empresários membros da aliança ou rede começarem a interagir e participar de seu funcionamento poderão ter dificuldades de adaptação ao novo padrão de tomada de decisão ou estilo de liderança. Assim, as evidências mostram que a liderança é fundamental para o êxito na formação de redes interorganizacionais e, também, na construção da confiança.

\subsubsection{Confiança durante formação de redes interorganizacionais horizontais}

No início da formação de redes, geralmente, predomina um ambiente de incertezas e dúvidas sobre os novos empreendimentos e a confiança é tênue, mas tende a fortalecer-se quando o grupo passa a conhecer-se melhor, conforme Tabela 4.

Tabela 4: Fatores de confiança no processo de formação de redes

\begin{tabular}{l|c|c|c|c|c|c|c|c}
\hline Fatores & NR & $\begin{array}{c}\text { DT } \\
(\mathbf{1})\end{array}$ & $\begin{array}{c}\text { D } \\
\mathbf{( 2 )}\end{array}$ & $\begin{array}{c}\mathbf{I} \\
\mathbf{( 3 )}\end{array}$ & $\begin{array}{c}\mathbf{C} \\
\mathbf{( 4 )}\end{array}$ & $\begin{array}{c}\text { CT } \\
\mathbf{( 5 )}\end{array}$ & Média \\
\hline $\begin{array}{l}\text { Ambiente favorável à expressão de dúvidas e } \\
\text { divergências }\end{array}$ & 4 & 1 & 9 & 13 & 21 & 19 & $3,76(3)$ \\
\hline $\begin{array}{l}\text { Clima de desconfiança e incerteza sobre os } \\
\text { resultados }\end{array}$ & 5 & 10 & 10 & 14 & 23 & 5 & $3,05(5)$ \\
\hline Debate cordial e democrático & 3 & 2 & 0 & 6 & 20 & 36 & $4,44(2)$ \\
\hline $\begin{array}{l}\text { O processo de debate aumentou o conhecimento } \\
\text { e a confiança }\end{array}$ & 3 & 1 & 0 & 3 & 25 & 35 & $4,52(1)$ \\
\hline A confiança no início da formação era tênue & 3 & 1 & 8 & 22 & 22 & 11 & $3,59(4)$ \\
\hline
\end{tabular}

Fonte: Elaborado pelos autores 
Os achados da pesquisa mostram existir um clima de desconfiança e incertezas, com média de 3,05, entre os empresários, quanto aos resultados futuros do novo empreendimento, o que confirma, por consequência, ser tênue a confiança quando o grupo inicia o trabalho de formar a rede, com posição média de 3,59 dos respondentes. A mesma percepção é evidenciada pelos entrevistados. "Antes todos eram concorrentes, deste modo, a confiança é fraca." (F1). Verifica-se que promover a mudança cultural de concorrente para parceiro é um processo difícil e relativamente demorado. Em síntese, a fase de constituição da rede representa mudar a forma de pensar e de agir, algo desafiador para as empresas consolidadas e maduras.

Os dados da pesquisa também mostram que o grupo já se conhecer ajuda na construção da confiança. Segundo os primeiros dirigentes das redes $A$ e $B$, pelo fato de essas redes terem sido gestadas dentro dos respectivos sindicatos e da rede $B$ e $D$, que uniu um grupo de conhecidos, 0 processo de construção da confiança foi facilitado. "A formação da rede ocorreu num clima de confiança absoluta, onde cada um podia expor suas ideias, sabendo que seria ouvido." (A1).

Independentemente do conhecimento prévio ou não dos participantes, a construção da confiança é um processo coletivo que ocorre em ambiente de debate aberto e franco que possibilite a todos expressarem suas dúvidas e anseios. Os dados confirmam que a construção das redes pesquisadas ocorreu em ambiente de diálogo aberto e democrático com indicação média de 4,44 em uma escala de cinco pontos, conforme Tabela 4. Esse clima de abertura e de franqueza teve influência positiva no aumento da confiança junto aos empresários, com aprovação quase unânime dos entrevistados, evidenciada pela média de 4,52.

Neste estágio, em virtude do aumento do nível de confiança, as partes chegam a um acordo quanto às obrigações e às regras para a ação futura no relacionamento entre as empresas, criando valores, estabelecendo as características e a estrutura de governança. Outro entrevistado declarou: "Na época da formação da rede, o grupo estava muito preocupado no estabelecimento das regras do jogo, e, principalmente, tornar a rede reconhecida pelos seus valores de idoneidade, 
respeito e seriedade." (Primeiro Presidente da Rede B). Essa orientação consolidou a confiança no grupo e ultrapassou as fronteiras da rede e está no mercado. Assim, uma rede tem mais chances de sucesso quando é alicerçada em torno de valores, de objetivos comuns e da criação de regras e instrumentos formais, desenvolvidos em conjunto pelos participantes, os quais reforçam a confiança do grupo e reduzem a possibilidade de comportamentos oportunistas.

Os entrevistados, quando indagados sobre qual a importância da confiança na continuidade da rede, foram unânimes em afirmar que estavam seguros de que seus interesses individuais poderiam ser compartilhados com os objetivos dos ganhos comuns. "A formação de uma rede é o espaço apropriado à criação de ambiente favorável à circulação de informações e recursos importantes, que os empresários podem usar em beneficio de seu negócio." (C1).

Verificou-se, durante a pesquisa, que a confiança é uma construção social alicerçada em valores, respeito mútuo, tempo de convivência e conhecimento dos parceiros, que lhes permite construir relacionamentos saudáveis. Assim, os resultados evidenciam a importância da construção da confiança durante o processo de formação das redes, condição necessária para que cresçam e se consolidem no mercado.

\section{DISCUSSÃO DOS RESULTADOS}

Com base na literatura e no levantamento empírico de informações, esta pesquisa oferece algumas contribuições teóricas úteis para os empresários, gestores de empresas e acadêmicos no que se refere à formação de redes interorganizacionais horizontais.

\subsection{CONTRIBUIÇÕES SOBRE A FORMAÇÃO DE REDES DE EMPRESAS}

A procura de maior eficiência pode ser vista como uma forma de as redes existirem pela necessidade de as organizações se adaptarem a certas pressões contingenciais. Verificou-se que entre as principais contingências que pressionam as empresas a formar e participar em contexto de rede 
estão: necessidades de complementaridade de conhecimentos, de acesso a inovação e novas tecnologias e de benefícios econômicos advindos da parceria.

Nas redes pesquisadas, o acesso à inovação e ao conhecimento aparece como o benefício mais valorizado na criação da parceria. Assim, razões fortes não monetárias estão presentes na sua participação, tais como aprendizagem, troca de experiências, compartilhamento de conhecimentos e informações estratégicas, credibilidade organizacional e proteção contra a concorrência.

Outros motivos estão nos resultados proporcionados às empresas participantes pelo aprimoramento contínuo, com a finalidade de aumentar o valor agregado dentro do grupo, criando novos bens e serviços e/ou métodos para reduzir custos e aprimorar a eficiência.

Dessa forma, a necessidade de compartilhar recursos (intangíveis e tangíveis) aparece como uma das principais razões que pressionaram as empresas a participarem de redes, como consequência de inúmeros fatores, entre eles: a hostilidade ambiental que as empresas vinham enfrentando como juros altos, concorrência de grandes grupos e necessidade de acesso ao crédito; o baixo nível tecnológico das empresas; e a baixa capacidade de crescimento. As empresas, também, estão utilizando as redes como fonte de inovação, de serviço e de criação de valor ao cliente, bem como valorização no mercado e acesso a novos mercados, ganhos de escala, acesso a fornecedores, acesso à mídia, entre outros, o que, isoladamente, se tornaria, em curto prazo, muito oneroso, a essas organizações. Para além de outras razões de ordem estratégica ou operacional, de forma resumida, é possível identificar as seguintes razões para cooperar e formar redes: necessidade de enfrentar a concorrência; acesso a canais de distribuição estabelecidos; necessidade de entrada de novos mercados; redução de custos de produção e de desenvolvimento; compartilhamento de riscos; complementaridade tecnológica e de conhecimentos; difusão e transferência de tecnologia; aceleração na introdução de novos produtos e envolvimento de diferentes experiências e estilos de gestão.

A formação de redes de empresas não se encontra isenta de dificuldade na criação. Diversos fatores podem contribuir para dificultar o 
sucesso na construção de uma organização estruturada na forma de uma rede de empresas. Os mais importantes devem-se a dificuldades de criar um clima de confiança entre os participantes, de atrair os parceiros certos e de contar com a presença de pessoas preparadas para liderar o processo. Nesse sentido, o estudo evidencia que a presença de líderes comprometidos com a causa ajuda a superar essas dificuldades e contribui na condução do processo que assegura uma aprendizagem comum, extensível a todo o grupo, e facilita a circulação de conhecimentos no sentido de permitir, de forma eficiente, o estabelecimento de interação e de cooperação das diferentes entidades participantes.

Observaram-se, nos casos pesquisados, muitas dúvidas sobre a escolha de quem poderia fazer parte do grupo formador da rede. As principais razões sobre as incertezas estão vinculadas à ausência de clareza sobre o funcionamento do novo empreendimento e de quem teria o perfil para agir de forma cooperada. Limitar o número de participantes e convidar empresários já conhecidos para integrar o grupo formador da rede aparece entre as estratégias evidenciadas no estudo. Isso apresenta dupla vantagem: primeiro, o número reduzido de participantes facilita o trabalho da liderança na condução do processo e, em tese, minimiza a seleção de empresários oportunistas; e, segundo, atrair pessoas já conhecidas contribui na escolha de parceiros mais identificados com o perfil do grupo e agiliza a formação da rede.

Verificou-se o cuidado de levantar informações sobre a idoneidade e o potencial dos novos parceiros junto ao mercado. Essa postura atende ao objetivo de atrair parceiros que tenham condições de agregar valor ao relacionamento e a disposição para compartilhá-lo, com perfil de acordo com os objetivos da rede horizontal e de seus valores. Apesar de todo o cuidado, falhas ocorreram na escolha dos parceiros e possibilitaram casos de oportunismo. Uma das inferências do estudo é que o acerto na escolha dos parceiros constitui uma das possíveis explicações que sustentam o crescimento, o desenvolvimento e a continuidade das redes. Assim, escolher os parceiros certos tem influência positiva no processo de formação de redes, ajuda a liderança e contribui para a construção da confiança. 
A liderança tem influência positiva no processo de construção de redes. Sendo o novo empreendimento coletivo, o estilo de liderança da empresa hierárquica tradicional não tem a mesma eficiência em ambiente de redes. Verificou-se, pela pesquisa, que no processo de criação de redes o foco da liderança estava em construir relações pessoais que favoreciam o relacionamento e a construção da confiança, além de fomentar a motivação e a harmonia entre os atores envolvidos. Os dados mostram, ainda, a necessidade de uma liderança com conhecimentos específicos sobre 0 funcionamento da nova organização e de suas vantagens.

Outro ensinamento da pesquisa evidencia que a reputação do líder é altamente valorizada e vista como eficaz para orientar o grupo e resolver problemas de relacionamento comuns no processo de formação das redes. No entanto, a presença de líderes influentes e proativos não elimina a influência de outros participantes, que, em função de seu status ou pelo entusiasmo e crença no modelo cooperativo, têm influência forte sobre o grupo. Essa atmosfera de confiança contagia o grupo, pela sensação de construir algo útil e vantajoso para o futuro, contribuindo para a constituição da rede e o aparecimento do fenômeno, que se poderia denominar "liderança coletiva", aquela em que todos se sentem na obrigação de contribuir para que tudo dê certo.

Entretanto, dificuldades, incertezas e situações de desconfiança sobre o êxito de trabalhar de forma coletiva foram evidenciadas. Problemas de desmotivação, de assiduidade nas reuniões e a descrença sobre o sucesso do futuro empreendimento são fatos verificados nesse processo. No entanto, os achados confirmam que a liderança exerce forte influência nos relacionamentos, capaz de mudar a cultura individualista para uma cultura de parceria.

No que se refere à confiança, constatou-se que, no início da formação das redes, predominava um ambiente de incertezas e dúvidas sobre o novo empreendimento e a confiança era tênue, mas fortaleceu-se quando o grupo passou a conhecer-se melhor. A confiança é vista como uma força que nasce tímida no processo de formação de redes, e pode ser encorajada a partir de estrutura e contexto adequados e, com isso, criar um 
ambiente favorável à circulação de informações e recursos importantes, que os empresários podem usar em benefício de seu negócio.

Em síntese, a fase da constituição da rede representa mudar a forma de pensar e de agir, algo desafiador para as empresas já consolidadas e maduras. Os achados da pesquisa evidenciam que a construção das redes pesquisadas ocorreu em ambiente de diálogo aberto, democrático e de respeito entre os participantes. Esse clima de abertura possibilita que todos expressem suas dúvidas e anseios, com influência positiva no aumento da confiança no grupo e, como consequência, contribui no envolvimento de todos no agir coletivo e na fé de que as empresas participantes vão atingir os resultados esperados. O estabelecimento da confiança facilita ao grupo o acordo sobre as obrigações e as regras para a ação futura no relacionamento entre as empresas, criando valores, estabelecendo as características e a estrutura de governança. Assim, uma rede tem melhores chances de sucesso quando é alicerçada em torno de valores, de objetivos comuns, de criação de regras e instrumentos formais, desenvolvidos em conjunto pelos participantes, os quais reforçam a confiança do grupo e reduzem a possibilidade de comportamentos oportunistas guiados, geralmente, por uma visão imediatista. Os resultados confirmam a importância da construção da confiança desde o processo de formação das redes, condição necessária para seu crescimento e consolidação. Tais evidências confirmam que a confiança torna-se fator indispensável para o desenvolvimento de redes e que a sua sobrevivência está ligada à cultura da confiança, que nasce desde o começo da criação de redes.

\section{CONSIDERAÇÕES FINAIS}

O estudo trouxe contribuições teóricas sobre a formação das redes, assim, espera-se que elas possibilitem novas investigações sobre o tema, corroborando, ou não, os resultados deste trabalho. Deve-se destacar que as teorizações e evidências apresentadas visam a estimular o debate em torno dos fatores de gestão na formação de redes entre empresas. O delineamento teórico organizou a problematização conceitual sobre aspectos que são objeto de interesse no campo acadêmico dos estudos 
organizacionais: fatores que contribuem para a formação de redes de empresas, pauta de estudo no campo das ciências sociais e administrativas nos cenários nacional e internacional. Espera-se que o debate estabelecido sob a perspectiva abordada possa ser aprofundado em outros estudos, e que os resultados apresentados possam contribuir como fonte de orientação para outras pesquisas. Da mesma forma, os achados da pesquisa poderão contribuir não só como uma resposta às dificuldades de formação das redes, mas também para o avanço do conhecimento teórico sobre o fenômeno das redes e sua dinâmica de evolução e de adaptação aos novos ambientes competitivos.

Neste estudo, buscou-se trabalhar somente com redes interorganizacionais horizontais, dessa forma a pesquisa em outros ambientes e setores poderia contribuir para melhor compreensão dessa temática. Para a área organizacional, mais especificamente nas atividades de gestão, as evidências empíricas e as teorizações propostas poderão contribuir no momento de formar redes em contexto de cooperação. Ainda, espera-se que os achados sejam úteis para a formação de futuras redes. Como sugestão de estudos futuros, salienta-se a necessidade de pesquisas sobre os esforços de construção, gestão e manutenção de arranjos cooperativos, ainda pouco compreendidos. Os resultados oriundos deste trabalho deverão ser analisados, levando-se em consideração os fatores restritivos para este estudo, limitados a um número reduzido de casos, situados em determinada região geográfica. Suas contribuições visam trazer análises críticas sobre o processo de formação de redes. 


\section{REFERÊNCIAS}

Almeida Filho, N. (2005). Gestão de redes de cooperação interempresariais: em busca de novos espaços para o aprendizado e a inovação. Salvador: Casa da Qualidade.

Amato Neto, J.(1999, junho). Productive cooperation network as a competitive advantage for small and medium size firms in the state of São Paulo (Brazil). 44th ICBS - International Conference of Small Business, Nápoles, Itália.

Balestrin, A. (2005). A dinâmica da complementaridade de conhecimentos no contexto das redes interorganizacionais. Tese de doutorado. Universidade Federal do Rio Grande do Sul, Porto Alegre, RS, Brasil.

Balestro, M. V. (2004). Características estruturais e mecanismos de governança em redes de cooperação: apontamentos conceituais. In J. R. Verschoore (Org.). Redes de cooperação: uma nova organização de pequenas e médias empresas no Rio Grande do Sul. Porto Alegre: FEE.

Conklin, D. \& Tapp, L. A rede criativa. (2003). In: Chowdhury, S.. Administração do século XXI: o estilo de gerenciar hoje e no futuro. São Paulo: Pearson Education, p. 220-234.

Crook, C. (2012). Teoria da complexidade: compreendendo os efeitos de rede. In P. R. Kleindorfer, Y. Wind, \& R. Gunther, O desafio das redes: estratégia, lucro e risco (pp. 193-207). São Paulo: Bookman.

Cunha, I. J. (2002). Modelo para classificação e caracterização de aglomerados industriais em economias em desenvolvimento. Dissertação de Mestrado, Universidade Federal de Santa Catarina: Florianópolis, SC, Brasil.

Grewal, D. S. (2008). Network power: the social dynamics of globalization. Yale: Yale University Press.

Gulati, R. (1995). Familiarity breeds trust? The implications of repeated ties for contractual choice in alliances. Academy of Management Journal, $38(1), 85-112$.

Hair, J. F., Babin, B., Money, A. H., \& Samouel, P. (2005). Fundamentos de métodos de pesquisa em administração. Porto Alegre: Bookman.

Hill, L. A. (2003). Liderança como gênio coletivo. In S. Chowdhury, P. Senge, \& C. K. Prahalad, Administração no século XXI: o estilo de gerir hoje e no futuro (pp. 44-64). São Paulo: Pearson Education.

Keil, T. (2000). Strategic alliances - A review of the state of the art. Helsinki University of Technology, Institute of strategy and International Business.Working Paper Series. 
Kleindorfer, P. R., \& Wind, Y. J. (2012). O imperativo das redes: comunidade ou contágio? In P. R. Kleindorfer, Y. J. Wind, \& R. E. Gunther, $O$ desafio das redes: estratégia, lucro e risco em um mundo interligado (pp. 3-23). Porto Alegre: Bookman.

Lastres, H. M. M., \& Cassiolato, J. E. (2005). Glossário de arranjos e sistemas produtivos e inovativos locais. Rio de Janeiro: IE. Recuperado em 1 de maio, 2012, de http://redesist.ie.ufrj.br/glossario.php.

Leana, C. R., \& Pil, E. K. (2006). Social capital and organizational performance: evidence from urban public schools. Organization Science, $17(3), 353-366$.

Lipman-Blumen, J. (1999). Liderança conectiva: como liderar em um novo mundo de interdependências, diversidade e virtualmente conectado. São Paulo: Makron Books.

Palmer, R. E. (2012). Liderança intercultural em empresas globais em rede. In P. R. Kleindorfer, Y. J. Wind, \& R. E. Gunther, $O$ desafio das redes: estratégia, lucro e risco em um mundo interligado (pp. 49-63). Porto Alegre: Bookman.

Parmigiani, A., \& Rivera-Santos, M. (2011). Clearing a path through the forest: a meta-review of interorganiztional relationships. Journal of Management, 37(4), 1108-1136.

Pereira, B. A. D., Venturini, J. C., \& Visentini, M. S. (2006). Estrutura de relacionamentos horizontais em rede. Revista Eletrônica de Administração, 12(5), 1-20.

Provan, K. G., Fish, M. A., \& Sydow, J. (2007, June). Interorganizational networks at networks level: a review of the empirical literature on whole networks. Journal of Management, 33(3), 479-516.

Ritter, T., \& Gemünden, H. G. (1998). Die netzwerkende Unternehmung: Organisationale Voraussetzungen netzwerk-kompetender Unternehmen. Zeitschrift Fuhrung+Organisation, 67(5), 260-265.

Santos, F., Crocco, M., \& Lemos, M. B. (2002). Arranjos e sistemas produtivos locais em espaços industriais periféricos: estudo comparativo de dois casos brasileiros. Belo Horizonte: UFMG/Cedeplar. Recuperado em $x x$ de agosto, 2012, de http://www.cedeplar.ufmg.br/pesquisas/td/TD\% 20182pdf

Shipilov, A. V., Rowley, T. J., \& Aharonson, B. S. (2006). When do network matter? A study of tie formation and decay. In B. Silverman (Ed.), Ecology and strategy (vol. 23, n. 2, Advances in Strategic Management, pp. 481-515). UK: Emerald Group Publishing.

Verschoore, J. R. (2004). Redes de cooperação: concepções teóricas e verificações empíricas. In J. R. Verschoore, Redes de cooperação: uma nova organização de pequenas e médias empresas no Rio Grande do Sul (pp. 15-46). Porto Alegre: FEE. 
Verschoore, J. R. (2006). Redes de cooperação interorganizacionais: a identificação de atributos e benefícios para um modelo de gestão. Tese de Doutorado, Universidade Federal do Rio Grande do Sul: Porto Alegre, RS, Brasil.

Verschoore, J. R., \& Balestrin, A. (2008). Fatores relevantes para o estabelecimento de redes de cooperação entre empresas do Rio Grande do Sul. Revista de Administração Contemporânea - RAC, 12(4), 10431069.

Wegner, D., \& Padula, A. D. (2010). Governance and management of horizontal business networks: an analysis of retail networks in Germany. International Journal of Businessand Management, 5(12), 74-88.

Wegner, D., Maciel, A. C., Schmitt, C. L., \& Wittmann, M. L. (2004). Fatores críticos para a formação de clusters e redes de empresas: um estudo exploratório. Anais do Seminários em Administração - Semead, 7, São Paulo, SP, Brasil. 